\title{
The Progress of an American EHR-Part 1
}

\author{
Ralph Grams
}

Published online: 1 October 2011

(C) Springer Science+Business Media, LLC 2011

\section{Overview}

Billions of dollars are now beginning to flow into the medical informatics market in hopes of achieving a breakthrough in healthcare delivery. The goals are noble and altruistic, but only the details will show the potential advantages as well as the limitations. Should we really spend huge sums of money to automate a system that has never functioned well on a national basis? Should we attempt a huge integrated system when we have no useful prototype to follow as a model? Can the government be trusted to be a benign dictator?

\section{Current progress}

The scope of activity is frenetic. Government committees are meeting everywhere and new people are being hired. The number of different groups involved in this venture appears to enlarge daily. There are all sorts of new acronyms being created and each week we get a fresh reminder of what this "new healthcare order" will sound like. Here are just a sampling of the topics under change and the potential for destructive architectural modifications.

The Centers for Medicare and Medicaid have just launched a new web site for consumer evaluation of hospitals [1]. This concept has now been moved to the physician arena and will soon result in a physician comparison web site for consumers. How this evaluation

R. Grams ( $\square)$

Pathology and Medical Informatics,

College of Medicine University of Florida,

Gainesville, FL 32610, USA

e-mail: kqinc@aol.com is done is still not clear. It could make or break a physician and lead to increased liability if not carefully crafted. How does the government enter the medical market and not create winners and losers with this comparison site? How does an individual defend themselves against false claims and inappropriate evaluation? Here is a place where great wisdom must be shown and only the details will resolve these concerns. Needless to say, physicians are very concerned about this exposure and the potential for personal damage if this information is not correct or biased. Each of these intrusions into the practice of medicine is one more reason for a medial practitioner to quite and find something less risky to do.

The current regulations and legislation provides no hope for medical malpractice reform [2]. We continue to operate in a predatory market where the plaintiffs can sue with no penalties if they are unsuccessful. Legal fishing expeditions are going on everyday and the cost for malpractice insurance continues to escalate. Nothing in the informatics process is designed to mediate this problem and only more costs can be expected in the near future. Today, about fiftyfive cents of every malpractice dollar is spent on overhead costs. This useless expense produces higher health costs and makes the prediction of national healthcare costs unreliable. Here is another place where all the incentives are encouraging our doctors to try some other profession that has less liability and greater financial returns.

Another area of great concern is the assembly of a massive federal database of all healthcare records [3]. This central database is under the control of the Office of Personal Management (OPM). The goal of OPM is to provide management information for three federal programs: the Federal Employee Health Benefit Program, the National Pre-Existing Condition Insurance Program, and the Multi-State Option Plan. In addition to these groups, the 
data is to be provided to outside research teams and given to law enforcement. There are no clear guidelines about the process of release and no rules or clear directions about the personal identification data that could be used to track individuals. How do we secure this huge and potentially lucrative database that could make all of us a target for marketing and legal action? Do we trust the government to do the right things to protect us or are we going to require a much more distributed and protective system for data mining of our personal health records?

There is a continuing debate about the words "meaningful use". Although there appears to be some clarity in this issue, the devil remains in the details. This clarity is yet to come. What constitutes a meaningful user? How does a system vendor pay for all the changes that are going to be coming from the federal controls? Who will be wealthy enough to survive this meaningful abuse of our healthcare system?

As a further unfolding of all of the new government regulations, we now hear that all the funds a physician may receive for implementing a new certified EHR are now taxable income. That drops another $25 \%$ of the value of the money and a less than attractive incentive for new system purchase.

As a practical example of the state of medical practice in America, I must return to the local level and report on what I see happening to those in practice who have worked hard to build their patient clientele and have sacrificed many years to build office space and support a large staff of professionals who keep all these patient's happy. What is occurring is sad and very damaging to our future healthcare system. I see doctor's electing to go back to paper records and accept cash-only for all their patient care. They no longer want to have anything to do with the government or insurance companies. They are getting less-and-less and required to do more-and-more for free. They are also being held liable for an EMR that does not do what they want done and has a very high cost of operation [4]. These systems are expensive to buy and expensive to maintain. They feel they are only working for a government that is determined to control and manipulate their clinical judgment and eventually cut their salaries. This was clearly spelled out by a recent decision from The Centers for Medicare and Medicaid Services (CMS). As of January 1, 2011, all physician fees will be cut $24.9 \%$ [5]. Dr. Donald Berwick is the CMS administrator who is handling this cut and has made it perfectly clear that he intends to ration healthcare and take control of all American medical practice. This governmental arrogance is a very dangerous trend to see developing and will only accelerate if ObamaCare is not stopped and replaced by a more physician friendly approach.

\section{References}

1. Monegain, B., Healthcare It News. 10/29/2010.

2. Arvantes, J., AAFP News Now. 11/20/2010.

3. Vijayan, J., Computerworld. 11/4/2010.

4. Miliard, M., Healthcare It News. 9/27/2010.

5. Manos, D., Healthcare Finance News. 11/03/2010. 